\title{
Minimally invasive beating heart full coronary artery bypass in a patient with pancreatic ductal adenocarcinoma
}

\author{
Mazlum Şahin $\odot$ \\ Department of Cardiovascular Surgery, University of Health Sciences, Haseki Training and Research Hospital, Istanbul, Turkey
}

DOI: $10.18621 /$ eurj.431204

\begin{abstract}
There are various problems associated with cardiopulmonary bypass in cardiac operations of patients with cancer. Our patient was a 73-year-old male patient diagnosed with pancreatic ductal adenocarcinoma. Coronary angiography of the patient who was planned to undergo tumor surgery revealed severe anomalies extending to the proximal of the diagonal 1 at the left anterior descending artery osteal and diagonal 1 distinction. Minimally invasive off-pump direct coronary artery bypass was performed in the patient. The patient was discharged on the 4th postoperative day and he was operated with the cause of pancreatic cancer at the third week. We think that minimally invasive coronary bypass without cardiopulmonary bypass can be performed with delayed prevention of cancer treatment and faster healing in patients with cancer of various systems.
\end{abstract}

Keywords: Coronary artery disease, cancer, minimally invasive direct coronary artery bypass, beating heart coronary bypass

Received: June 6, 2018; Accepted: April 5, 2019; Published Online: June 30, 2019

$\mathrm{T}$ he mean age of patients with coronary artery bypass grafting $(\mathrm{CABG})$ is increasing day by day due to the progress of endovascular treatment methods. The advancing age causes additional diseases such as cancer in patients. Coronary artery revascularization is recommended in patients with coronary artery disease prior to the treatment of neoplasia and it is also known that coronary artery bypass grafting is a safe and effective method [1]. Pancreatic ductal adenocarcinoma has poor prognosis and surgical tumor resection is the only curative treatment [2]. In this study, we presented a patient with pancreatic cancer and coronary artery disease. Minimally invasive full coronary bypass was performed.

\section{CASE PRESENTATION}

A 73-year-old male patient was diagnosed with pancreatic adenocarcinoma and planned for distal pancreatectomy. Preoperative evaluation, coronary angiography showed a stenosis of $80 \%$ in the left anterior descending artery (LAD) osteal and $90 \%$ in the LAD-diagonal 1 (D1) bifurcation. The patient was operated for coronary bypass. The patient was positioned $30^{\circ}$ to the right lateral decubitus position. Right great saphenous vein graft was prepared. A left internal mammary artery (LIMA) was prepared from the fourth intercostal space with an $8 \mathrm{~cm}$ incision. The pericardium was opened from the thoracotomy

Address for correspondence: Mazlum Şahin, MD., University of Health Sciences, Haseki Training and Research Hospital, Department Cardiovascular Surgery, Istanbul, Turkey, E-mail: mzlmshn@gmail.com 


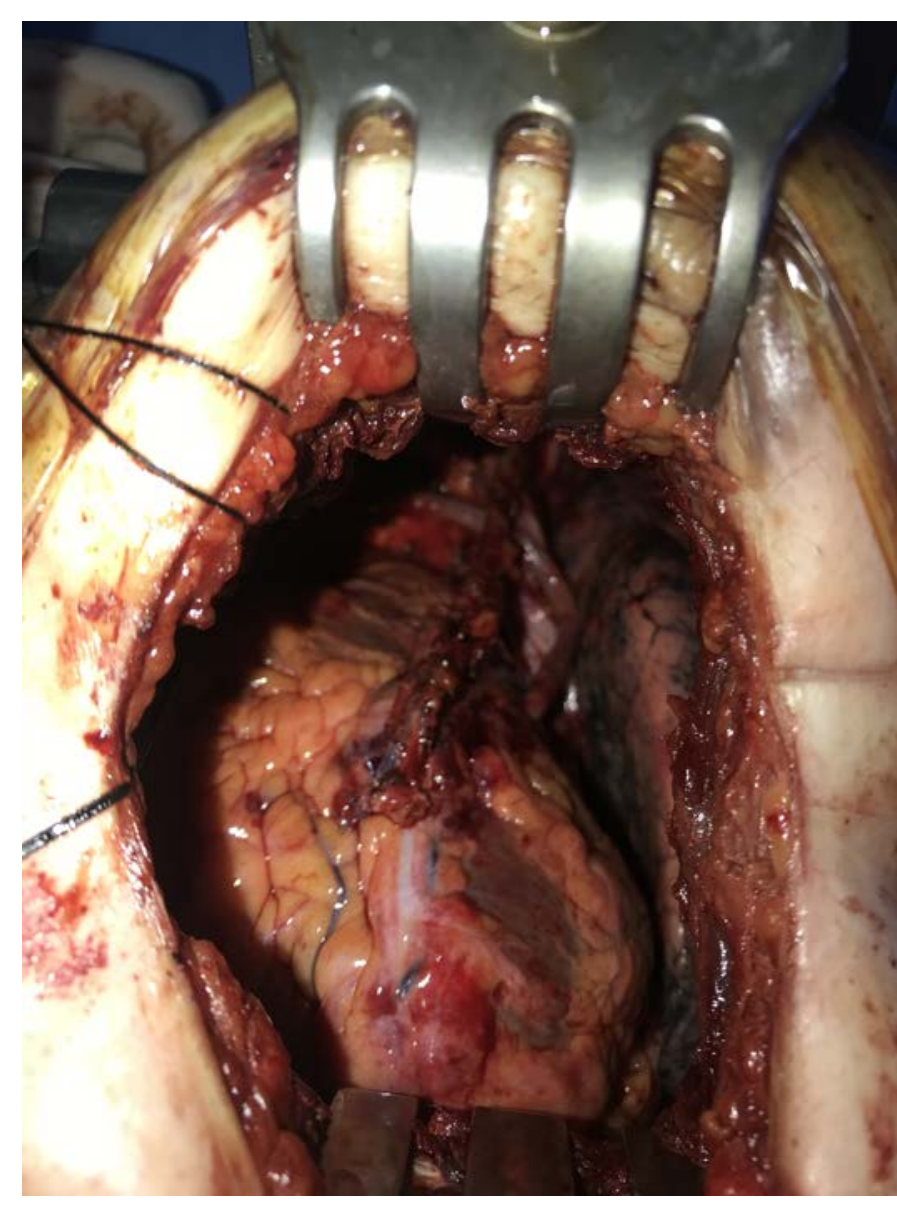

Figure 1. Intraoperative image shows completed anastomoses.

incision. Aorta prepared for proximal anastomosis. Proximal anastomosis was completed after lateral clamp placed on the aorta. LIMA-LAD and Aort-D1 distal anastomoses with saphenous vein graft were performed with the aid of a cardiac stabilizer (Figure 1). After the operation, the patient was transferred to intensive care unit. The patient was discharged on the fourth postoperative day. The patient underwent distal pancreatectomy 3 weeks after discharge.

\section{DISCUSSION}

CABG with extracorporeal circulation may cause metastatic spread of cancer in cancer patients, so it is emphasized that CABG is more suitable for these patients without cardiopulmonary bypass (CPB) pump $[3,4]$.

Surgery for coronary artery disease and malignancy can be performed simultaneously or in two phases. Both approaches have advantages and disadvantages. In a study conducted on a total of 350 patients by Darwazah et al. [5], they recommended a two-stage procedure [5]. We prefer to perform coronary bypass first.

If cancer patients have LAD or left main coronary lesion, coronary revascularization should be performed before cancer surgery [6]. Percutaneous coronary intervention (PCI) or $\mathrm{CABG}$ may be performed in coronary revascularization. Antiplatelelet therapy is recommended for at least 1 month in bare metal stents (BMS) and 6 to 12 months in drug-eluting stents (DES). In addition, 16\%-44\% restenosis was detected in BMS. Non-cardiac surgery under antiplatelelet treatment may cause high bleeding risk, surgical excision of antiplatelelet therapy may result in stent thrombosis. Waiting for 6 or 12 months may cause delayed treatment of cancer [7]. Our patient also had a LAD lesion and planned operation with the cause of pancreatic cancer.

Minimally invasive direct coronary artery bypass (MIDCAB) causes less pain, bleeding and infection. Besides this, patients can return to daily life faster [8]. In cancer patients in particular, the healing process is important for accelerating cancer treatment. That's why we decided to do MIDCAB. The patient was discharged on the 4th postoperative day and he was operated with the cause of pancreatic cancer at the third week.

\section{CONCLUSION}

In conclusion, if coronary artery disease is detected in cancer patients and coronary revascularization is planned, we think that minimally invasive coronary bypass can be performed in appropriate patients, patients can heal faster and cancer treatment can be started early.

\section{Informed consent}

Written informed consent was obtained from the patient for publication of this case report and any accompanying images.

\section{Conflict of interest}

The author declared that there are no potential conflicts of interest with respect to the research, authorship, and/or publication of this article. 


\section{REFERENCES}

[1] Hirose H, Amano A, Yoshida S, Nagao T, Sunami H, Takahashi A, et al. Coronary artery bypass grafting in patient with malignant neoplasm. Efficacy of coronary artery bypass grafting on beating heart. Jpn J Thorac Cardiovasc Surg 2000;48:96-100. [2] Åkerberg D, Ansari D, Andersson R. Re-evaluation of classical prognostic factors in resectable ductal adenocarcinoma of the pancreas. World J Gastroenterol 2016;22:6424-33.

[3] Tanaka H, Narisawa T, Hirano J, Suzuki T, Takaba T. Efficacy of off-pump coronary artery bypass grafting in patients requiring noncardiac operations. Kyobu Geka 2001;54:1107-11.

[4] Petrova VV, Osipova NA, Donakova IS, Edeleva NV, Kudriavtsev SB. [Choice of treatment strategy for a patient with rectal cancer and severe concomitant disease (İHD)]. Anesteziol
Reanimatol 2001;5:73. [Article in Russian]

[5] Darwazah AK, Osman M, Sharabati B. Use of off-pump coronary artery bypass surgery among patients with malignant disease. J Card Surg 2010;25:1-4.

[6] Krone RJ. Managing coronary artery disease in the cancer patient. Prog Cardiovasc Dis 2010;53:149-56.

[7] Kałuza GL, Joseph J, Lee JR, Raizner ME, Raizner AE. Catastrophic outcomes of noncardiac surgery soon after coronary stenting. J Am Coll Cardiol 2000;35:1288-94.

[8] Holzhey DM, Jacobs S, Mochalski M, Walther T, Thiele H, Mohr FW, et al. Seven-year follow-up after minimally invasive direct coronary artery bypass: experience with more than 1300 patients. Ann Thorac Surg 2007;83:108-14. 